\title{
Community clinics: an effective avenue for delivering primary healthcare services to urban vulnerable population under NUHM during COVID-19 era and beyond
}

\author{
Sudipta Basa*, Basab Gupta \\ Urban Health Division, MoHFW, New Delhi, India \\ Received: 14 December 2020 \\ Accepted: 13 January 2021 \\ *Correspondence: \\ Sudipta Basa, \\ E-mail: sudipta.basa@gmail.com \\ Copyright: () the author(s), publisher and licensee Medip Academy. This is an open-access article distributed under \\ the terms of the Creative Commons Attribution Non-Commercial License, which permits unrestricted non-commercial \\ use, distribution, and reproduction in any medium, provided the original work is properly cited.
}

\begin{abstract}
The urban population in our country is increasing rapidly and represents the 2-3-4-5 syndrome. It is estimated that by 2031, there would be about 600 million people living in urban India. The health of the urban poor is considerably worse off than the urban middle and high income groups and is maybe even worse than the rural population. Even after more than 40 years of Alma Ata's declaration the main focus on provision of Primary Healthcare based on principles of social inclusion, equity and comprehensiveness has lost some attention in-between. With the abrupt and sudden outbreak of COVID-19, has put the health system into crisis all over the country especially in urban areas. Lakhs of vulnerable population in slum areas had to suffer in absence of provision of basic primary health care (PHC) services during the lockdown period. In this article we present the need of community clinics under NUHM, an effective avenue for delivering PHC services for vulnerable population in this ongoing COVID-19 pandemic era and beyond.
\end{abstract}

Keywords: COVID-19, Primary Healthcare, NUHM, Vulnerable population

\section{INTRODUCTION}

The theme of World Health Day (WHD), 2010 was "Urbanization and Health with campaign focussing on 1000 cities-1000 lives" and WHD (2019) Universal Health Coverage (UHC) with focus on primary health care (PHC) with campaign on UHC: Everyone, Everywhere. ${ }^{1}$ The urban population growth in India is increasing rapidly and represents the 2-3-4-5 syndrome. It is projected to increase from $31 \%$ (2011) to $46 \%$ (2030). It has been estimated that $30 \%-40 \%$ of population in metros lives in slum or slum-like habitation. ${ }^{2,3}$

The city is home to both opportunities and obstacles; with better planning we can create safer cities, prevent injuries and save lives. The health of the urban poor is considerably worse off than the urban middle and high income groups and is maybe even worse than the rural population. The basic amenities such as water, toilets, sewers, drainage, waste collection and adequate housing are already in short supply or non-existent in slum areas. Further, space constraints, violence, and overcrowding in slums are very common. ${ }^{4}$

So when the basic amenities are in compromised situation than how can the health indicators of this segment of population will be better. Poor sanitary conditions in slums contribute to the high burden of disease here. Twothirds of the urban poor households do not have access to toilets and nearly 40 percent do not have piped water supply at home. Malnutrition among the urban poor children was worse than rural areas. Only 42 percent of the slum children received all the recommended vaccinations. Over half 56 percent of the child births 
occurred at home, in slums, putting the life of both the mother and new born to serious risk. ${ }^{3}$

But one needs to comprehend that the cost of outpatient services delivered through (PHC) is 5 to 8 times lower than when the same services are availed at higher levels of facilities. ${ }^{5}$ As per the National Sample Survey for 2014 , only $3.9 \%$ people in urban areas accessed this vast network of peripheral public health facilities for healthcare needs other than childbirth. ${ }^{6}$

Even after more than 40 years of Alma Ata's declaration the main focus on provision of PHC based on principles of social inclusion, equity and comprehensiveness is lost some attention in-between. ${ }^{7}$ With the abrupt and sudden outbreak of COVID-19, has put the health system into crisis all over the country especially in urban areas. Lakhs of vulnerable population in slum areas had to suffer in absence of provision of basic primary health care (PHC) services during the lockdown period.

Further how National Urban Health Mission can help in strengthening health systems through improved provision of basic primary health care (PHC) services at slum level has been discussed.

\section{WHY WAS THE NEED OF NATIONAL URBAN HEALTH MISSION (NUHM)?}

Though many components of the National Rural Health Mission (NRHM) cover urban areas as well. The only limitation has been the fact that norms for urban area primary health infrastructure were not part of the NRHM, setting a limit to support for basic health infrastructure in urban areas. Municipal Corporations, Municipalities, Notified Area Committees and Nagar (Town) Panchayats were not units of planning under NRHM, with their own distinctive normative framework. ${ }^{8}$ Therefore the launch of NUHM in 2013, marks an important landmark, in the country's step towards the UHC. One of the main objectives of NUHM is to address the primary health care needs of the urban poor and vulnerable population and to provide special emphasis on improving the reach of health care services to these vulnerable groups. Though living in urban area offer many opportunities, including potential access to better health care. However, today's urban environments reflects health risks and introduces new hazards also. Health problems in cities include issues of water, environment, violence and injury, noncommunicable diseases such as cardiovascular diseases, cancers, diabetes and chronic respiratory diseases, unhealthy diets and physical inactivity, harmful use of alcohol. Apart from the above, urbanization also affects the spread of communicable diseases including tuberculosis, malaria and HIV/AIDS etc. But still the poor in India either chose for higher level facilities for PHC needs (an issue of subsidiarity) or attend a private provider (resulting in the out of pocket expenditure) both the situations are not good for health system.
The Government spending on health has also been another recognized challenge. The National Health Policy 2017 focuses on strengthening PHC, increased government funding for health to $2.5 \%$ of GDP by 2025 and that two-third or more government budget be allocated for PHC services. ${ }^{9}$ And now the Astana Declaration, 2018 has become a new rallying point behind PHC. ${ }^{10}$ The Astana Declaration (2018), 40 years after Alma Ata, was passed to provide a new impetus for strengthening PHC and to accelerate progress towards the Sustainable Development Goals (SDGs).The focus on individual diseases and vertical programmes resulting in siloed approaches has affected the health care of vulnerable population to greater extent. Thus, the three pillars of PHC endorsed in Astana declaration like community empowerment, multisectoral policies and actions and integrated delivery of quality primary care and public health services will play key role in addressing health issues in urban areas.

The Government in India announced Ayushman Bharat Program (ABP) in February 2018 with two components of (a) Health and Wellness Centres (HWCs) to strengthen $\&$ deliver comprehensive Primary Health Care (CPHC) services for entire population and (b) PradhanMantri Jan ArogyaYojana (PMJAY) covering $40 \%$ of the poorest and most vulnerable individuals in the country for secondary and tertiary care facilities ${ }^{11}$.In a shift, ABP has the beneficiaries beyond traditional approach of targeting 'below poverty line' (BPL) population. Inclusion of 'vulnerable and deprived population' identified through Socioeconomic and Caste Census (SECC) will nearly double the number of people to be benefited. ${ }^{12}$ The aim of $\mathrm{CPHC}$ is to provide a seamless continuum of care that ensures the principles of equity, quality, universality and no financial hardship. Keeping the above in view we need to understand why the following in context to urban areas especially is more important. The challenges in urban areas are very different from those in rural areas. We need to understand the following:

\section{Who are the vulnerable population?}

Urban populations and the urban poor are far from being homogeneous and consist of several sub-groups that differ socially, economically and geographically. Such vulnerabilities may be (1) Residential vulnerability includes those residing in slums not served by any form of public services like sanitation, drinking water and drainage (2) Social vulnerability includes categories such as female/minor headed households, the aged, people with disability and illness (3) Occupational vulnerability includes those who do not have access to regular employment, without skills or formal education hence get engaged into informal and causal labour with uncertain earnings such as construction workers, sex workers, brick kiln workers, rickshaw pullers, street vendors, domestic workers etc. ${ }^{8}$ 


\author{
What is the Health Seeking Behaviours of vulnerable \\ population?
}

The physical environment of any urban slum makes it a petri dish for any kind of disease transmission. Many urban informal settlement residents rely on informal health providers as their first entry into the health care system, either due to cost, trust, or access issues. ${ }^{4}$ Cost, timings, distance, attitude of health providers and other factors put the secondary care and private sector facilities out of reach of most of the urban poor. The reliance of these people on quacks and pharmacies for treatment worsen during any emergency or outbreak situation even more.

The evidence is well supported with around $6 \%$ do not seek health care due to financial reasons and among those who do, experiences are often financially catastrophic and impoverishing. Household OOPE in India is $67 \%$ of total health expenditure. ${ }^{13,16}$

\section{What is the service delivery mechanism under NUHM?}

The healthcare services have been made available by establishing the Urban Primary Health Centres (UPHC) and Urban Community Health Centres (UCHC).At present the UPHC covers a population of about 50,000 which acts as the first point of contact to the urban poor in slums whereas the UCHC covers a population of about 5 lakhs and acts as referral point. There are Outreach activities in the form of Urban Health and Nutrition Days and Special Outreach Session held monthly and quarterly respectively as per the need of the community. Unlike rural areas, establishment of sub-centre has not been envisaged for urban areas under NUHM. ${ }^{8}$ Therefore the focus on provision of primary health care services at door step level in community is of utmost importance especially for slum dwellers and vulnerable population.

\section{How can the Municipal Corporation/Urban Local Body play key role in addressing the health issues?}

The Twelfth Schedule of $74^{\text {th }}$ Constitutional Amendment Act specifies the function of public health to be transferred under control of City Governments. The coordination between the State and City governments is crucial for effective decentralised management at the local-level. Strong political and executive leadership is necessary to enable City Governments to respond quickly at the time of any health emergency situation. This can only be ensured when authority lies with the Commissioner, Mayor, and the City Councillors to take decisions for the effective management of crises in the city.

In turn, this will further allow for better planning and quick action at the respective zonal, ward, and local area levels. A holistic approach with supportive collaboration of activities of various stakeholders is must for successful implementation of comprehensive PHC in urban areas.

\section{Why the emphases on the requirement of healthcare centre below UPHC in urban areas?}

Based on the recent evidences and experience related to COVID-19 with context to slum areas throws an important question that "Can the current urban healthcare delivery system address the CoVID-19 like situation in slum areas" in future? The public sector urban health delivery system, especially for the poor, has so far been sporadic, far from adequate and limited in its reach although urban areas have a greater number of doctors per thousand population as compared to rural areas. To be more precise, the public health system catering to the urban slum dwellers have historically been ill-equipped to handle health crisis.

When the provision for routine PHC services is sparse and during any epidemic situation e.g COVID-19etc, we don't have the answer about how to cater the health care needs of urban poor/ vulnerable population, it then leads to inequality and inequity in access of health care. Therefore there is felt need that unlike in rural areas, there should be the first point of contact between the slum community and the health system in urban areas also in form of healthcare centre or community clinics on the lines of sub-centre to focus on health care needs of vulnerable population, that can improve their long-term well-being.

We have made commitment to UHC through National Health Policy, 2017 and PHC is an important component in path to UHC. COVID-19 pandemic has further underscored the need for strengthening the primary health care at the earliest. Evidence suggests that a strengthened PHC system performs better when supported by wellfunctioning hospital services/system with two way referral. The entire process should be guided by use of evidence to scale up interventions and services. In the recent years, a number of Indian States/UT have started innovative initiatives such as (Mohalla Clinics, Delhi, Basthi Dawakhana, Telangana, Family Health Centres, Kerala, Atal Clinics, Jharkhand, Sanjivani Clinics, Madhya Pradesh, Ama Clinics, Odisha, Appla Clinics, Maharashtra and Janata Clinics of Rajasthan) to strengthen PHC services which provide learnings for ABHWC and potential harmonization between state initiatives and HWCs. ${ }^{17,14}$ These community clinics are proofs that people prefer them over larger hospitals if service provision is assured. These initiatives have become popular amongst people and brought poor, marginalized, women and children to government health care system thus serving as connecting link.

\section{CONCLUSION}

There is a global consensus that universal health coverage can only be achieved on the foundation of stronger primary health care system. Thus as we march towards achieving UHC, strong policy decisions is very much needed in context to urban areas to set up health care 
facilities below UPHC in form of community clinics, functioning on the parameter of $\mathrm{AB}-\mathrm{HWC}$ to deliver quality PHC services. The need of empowering the City Governments to respond to any health crises at the locallevel will not only increase the effectiveness of our response to the current pandemic, but also ensure that our cities/towns are prepared for the future.

Thus an equitable approach to arresting the COVID-19 pandemic must change standard ways of treating the urban poor, create more participatory governance, improve the delivery of essential services including health care, and invest new resources to ensure urban informal settlements benefit in the long term.

We hope the suggestions can not only respond to the urgent needs of this ongoing COVID-19 pandemic and prevent millions of deaths but also offer a more humane and equitable approach to improving the health and living conditions of the urban poor / vulnerable population.

\section{ACKNOWLEDGEMENTS}

The authors would like to thank all the authors of those books, articles, and journals that were referred in preparing this manuscript.

Funding: No funding sources Conflict of interest: None declared

Ethical approval: Not required

\section{REFERENCES}

1. World Health Organization. World Health Day. World Health Organization; 2010 and 2019. Available from: https//www.who.int/campaigns/world health day.

2. Kumar S, Sanjiv Kumar, Basab Gupta. Urban Health: Needs Urgent Attention. Indian J Public Health 2018;62:214-7.

3. Yadav K, Nikhil SV, Pandav CS. Urbanization and Health Challenges: Need to Fast track launch of the National Urban Health Mission. Ind J Community Medic. 2011;36:3-7.

4. Corburn J, Vlahov D, Mberu B, Riley L, Caiaffa T W, Rashid FS, et al. Slum Health: Arresting COVID-19 and Improving Well-Being in Urban Informal Settlements. J Urban Health 2020.

5. Lahariya C. More better, faster \& sustained: Strengthen primary health care to advance universal health coverage. Indian Journal of Medical Research. 2019;149:433-6.

6. MoSPI. Key indicators of social consumption in India: Health. NSS 71st round. January - June 2014. New Delhi: Government of India, Ministry of Statistics and Programme Implementation; 2015. Available at: http://mospi.nic.in/sites/default/files/publication_rep orts/KI_Health_75th_Final.pdf.
7. Declaration of Alma-Ata. International Conference on Primary Health Care, Alma-Ata, USSR, 6-12 September 1978. Available at: https://www.who.int/publications/almaata_declarati on_en.pdf?

8. Ministry of Health and Family Welfare, Government of India. National Urban Health Mission Framework for implementation; May 2013. Available from: http://www.nhm.gov.in/images/pdf/NUHM/Implem entation_Framework_NUHM.pdf

9. Government of India. National Health Policy 2017. New Delhi: Ministry of Health and Family Welfare, Government of India; 2017. Available from: https://www.nhp.gov.in/nhpfiles/national_health_po licy_2017.pdf.

10. Declaration of Astana. Global Conference on Primary Health Care. Astana, Kazakhstan, 25-26 October 2018. Available at: https:// www.who.int/docs/default-source/primaryhealth/declaration/gcphc-declaration.pdf.

11. Ayushman Bharat. Comprehensive primary health care through health and wellness centers. Operational guidelines. New Delhi: Ministry of Health and Family Welfare, Government of India; 2018.Available

from: http://nhsrcindia.org/sites/default/files/Operational\% 20Guidelines\%20For\%20Comprehensive\%20Prima ry $\% 20 \mathrm{Health} \% 20 \mathrm{Care} \% 20$ through $\% 20 \mathrm{Health} \% 20 \mathrm{a}$ nd\%20Wellness\%20Centers.pdf.

12. Lahariya C. Ayushman Bharat' Program and Universal Health Coverage in India. Indian Pediatrics. 2018; 55: 495-506.

13. Govt of India. National Health Accounts 2015-16. Ministry of Health and Family Welfare, Government of India, Oct 2018.Available from: https://main.mohfw.gov.in/sites/default/files/NHA_ Estimates_Report_2015-16_0.pdf.

14. Lahariya C. Health \& Wellness Centers to Strengthen Primary Health Care in India: Concept, Progress and Ways Forward. The Indian Journal of Pediatr. 2020:1-14.

15. World Health Organization. The transformative role of hospitals in the future of primary health care. Technical series on primary health care. Geneva: WHO. 2018. Available at: https://www.who.int/docs/default-source/primaryhealth-care-conference/hospitals.pdf.

16. Bakshi H, Sharma R, Kumar P. Ayushman Bharat Initiative: What we stand to Gain or Lose! Indian J Community Medic. 2018;43:63-6.

17. State Programme Implementation Plans (SPIP), FY2018/2019/2020.Available http://www.nhm.gov.in.

18. Govt of Kerala. Family Health Centres. Can Kerala's Bold Experiment to Overhaul Public Health from Bottom up Succeed? Available at: https://scroll.in/pulse/852553/can-keralas-boldexperiment-to-overhaul-public-health-from-bottomup-succeed. 
19. Govt of Maharashtra. Aapla Clinics. Available at: https://indianexpress.com/article/cities/mumbai/likedelhi-maharashtra-to-get-mohalla-clinics-forprimary-healthcare-5603945/.

20. Govt of Rajasthan. Janata Clinics of Rajasthan. Available at: https://government.economictimes.indiatimes.com/n ews/healthcare/rajasthan-healthcare-to-go-digitalwith-janta-clinics-launch-in-jaipur/71670391.

21. Govt of MP. Sanjivani Clinics. Available at: https://www.freepressjournal.in/indore/inspired-bydelhis-mohalla-clinics-mp-govt-to-inaugurate-firstsanjeevani-clinic.

22. Govt of Telangana. Basthi Dawakhanas. Available at: https://telanganatoday.com/hyderabads-bastidawakhanas-a-boon-for-poor.

23. Basthi Dawakhana an urban health initiave of Telangana. Available nhm.gov.in`new_updates_2018.
24. Govt of Jharkhand. Atal Mohalla Clinics in 15 districts. Available at: https://ehealth.eletsonline.com/2019/08/jharkhandgovt-starts-atal-mohalla-clinics-in-15-districts.

25. Govt of Odisha. AMA Clinic Yojana. Available at: https://odishanewsinsight.com/tag/ama-clinicyojana.

26. Govt of NCT of Delhi. Aam Aadmi Mohalla Clinic. Available at: http://health.delhigovt.nic.in/wps/wcm/connect/doit _health/Health/Home/Directorate+General+of+Heal th+Services/Aam+Aadmi+Mohalla+Clinics.

Cite this article as: Basa S, Gupta B. Community clinics - An effective avenue for delivering primary healthcare services to urban vulnerable population under NUHM during COVID era and beyond. Int $\mathbf{J}$ Community Med Public Health 2021;8:1003-7. 